JOSÉ DIEZ DE CASTRO Y CARMEN REDONDO LÓPEZ (Pirámide. Madrid. 1996)

\title{
ADMINISTRACIÓN DE EMPRESAS. Libro de actividades: ADMINISTRACIÓN DE EMPRESAS. Casos, cuestiones y lecturas
}

Las siguientes líneas tienen como finalidad el realizar una breve reseña de la obra de reciente aparición elaborada por los Profesores José Díez de Castro y Carmen Redondo López. Estos libros, introductorios al ámbito empresarial, tienen un marcado carácter didáctico, pudiendo ser utilizado tanto en cursos regulares de introducción a la Administración, como por Licenciados de otras carreras y profesionales autodidactas que requieran de unas nociones accesibles de la gestión empresarial.

El trabajo desarrollado por los Profesores Díez de Castro y Redondo López tiene su culminación en una obra rigurosa de brillante presentación y que, a nuestro juicio, viene a cubrir un cierto vacío existente en el campo de la Administración de Empresas. De hecho, los más recientes manuales de Administración al uso editados en castellano: Hampton, D. R. (1989); Donnelly, J., Gibson, J.L. e Ivancevich, J. (1994); Stoner y Freeman, R. (1994); Koontz, H. y Weihrich, H. (1994); Robbins, S. (1994) evidencian la carencia de manuales publicados por tratadistas de nuestra disciplina en España. No obstante, la existencia de prestigiosos manuales en nuestro

* Profesor Titular del Departamento de Administración de Empresas y Marketing. Universidad de Sevilla. 
campo no significa que el manual objeto del presente análisis carezca de una clara diferenciación positiva. De hecho, esta obra presenta al menos dos grandes ventajas que la hacen una herramienta imprescindible para el estudio de la gestión empresarial:

* De una parte, su estilo de fácil acceso y comprensión sin que adolezca de falta de rigor, junto con el uso de referencias selectas y concretas lo convierten en un manual de consulta muy atractivo para el lector y/o alumno. Además, casi todos los temas desarrollados culminan contestando implícitamente a la pregunta que, por regla general, todos los estudiantes sin experiencia más se formulan: ¿y esto para qué sirve?, lo que estimula de forma notable la capacidad del alumno para trasladar lo aprendido a otros ámbitos.

* De otra, como los autores señalan, su sintonía con las necesidades de formación y los objetivos docentes típicos en la Universidad Española para un curso de introducción a la actividad directiva, junto con la posibilidad de disponer de material auxiliar hace que los docentes encuentren un instrumento muy útil para el desarrollo de su labor.

El manual teórico "Administración de Empresas" comprende 26 capítulos estructurados en 8 bloques. Cada capítulo del libro presenta, a su vez, la siguiente estructura: una justificación teórica del mismo, una explicación de los conceptos concisa y ajustada a las necesidades didácticas, cuestiones de razonamiento, un caso, vocabulario del capítulo, bibliografía comentada y, por último, bibliografía recomendada. Un análisis pormenorizado de los bloques y su contenido nos ofrecen una visión más profunda del alcance de la obra.

\section{Parte primera: "Presente y pasado de la Administración" desarro-} llada a lo largo de tres capítulos, tiene como finalidad situar al lector en el mundo de la Administración, su historia y en la vida cotidiana de los principales integrantes, los administradores. El capítulo primero -Administración: un introito- ofrece una perspectiva sobre la figura humana del administrador y sienta las bases para el estudio de la Administración. El Capítulo segundo -Los precursores- lleva a cabo un repaso de las obras de los principales autores clásicos de la Administración. Por último, en el capítulo tercero, se describen las principales escuelas del pensamiento administrativo.

Parte segunda: "Limitantes de los administradores". Esta segunda parte del libro, a través de dos capítulos, transmite una idea básica: la capa- 
cidad decisoria del individuo está restringida. En este sentido, el capítulo cuarto recoge las fuerzas que, de manera directa o indirecta, afectan al ejercicio directivo. Sin embargo, los condicionantes que acotan la capacidad de decisión de los directivos no están limitados a éstos, otras fuerzas, éstas inmateriales, añaden nuevas restricciones al trabajo diario de gestión dentro de las empresas. En esta línea, el capitulo quinto se detiene a analizar tres grandes aspectos: la cultura organizacional, la ética en los negocios y la responsabilidad social.

Parte tercera: "Planificación". Una vez iniciados en el campo de la Administración, los manuales suelen dedicar una serie de bloques al análisis secuencial de las diferentes funciones directivas. Por ello y dentro de este tercer bloque, los autores se centran en la planificación pues, sin ésta, el resto de funciones no podrían desarrollarse de forma lógica y racional. En palabras de Koontz y Weihrich (1994): "La planificación permite salvar la brecha que nos separa del sitio a donde queremos ir. Hace posible que ocurran cosas que de otra manera no hubieran sucedido". Una revisión de este bloque nos permitirá conocer las fases o etapas del proceso de la planificación, su naturaleza y propósito así como el análisis de la planificación estratégica. Al describir los pasos en la planificación se constata que su núcleo es realmente el proceso de la decisión, de aquí que es frecuente incluir su análisis en este bloque. Por ello, el análisis detallado de la toma de decisiones así como de un conjunto de técnicas de ayuda al decisor cierran este primer bloque dedicado a las funciones gerenciales.

Parte cuarta: "Organización". Segunda de las funciones directivas abarca la definición de los parámetros estructurales así como la fijación de las relaciones jerárquicas, de comunicación y de influencia entre personas y grupos. Como señalan Donnelly, Gibson e Ivancevich (1994): "El propósito de la función de organizar es lograr un esfuerzo coordinado a través del diseño de una estructura de relaciones entre las tareas y la autoridad. Los dos conceptos clave son diseño y estructura; en este contexto, diseño implica que los gerentes deben hacer un esfuerzo consciente para determinar con anticipación la manera en que trabajan los empleados, mientras que la estructura se refiere a las relaciones y aspectos más o menos estables de la organización". Esta función directiva se desarrolla a lo largo de cuatro capítulos: división del trabajo y estructura, autoridad y poder, adaptación de las estructuras y, por último, grupos en las organizaciones. 
Parte quinta: "Rec̄ursos humanos". Una vez que se ha llevado a cabo las funciones de planificación y organización, disponemos de unas metas, unas vías para su logro y un diseño de puestos de trabajo necesarios. Estos puestos serán ocupados por personas, por lo que captar, ubicar y mantener las personas adecuadas para cada posición implica el ejercicio correcto de un gran número de actividades cuyo análisis se desarrolla en dos capítulos de una forma exhaustiva. Por último, se incluye en este bloque el estudio del cambio, conflicto y estrés, por cuanto estos tres temas inciden de manera directa e indirecta sobre los resultados de la empresa u organización.

Parte sexta: "Dirección". Este bloque se ocupa de los aspectos más interpersonales de la administración de los recursos humanos. En este sentido, un buen ejercicio de las funciones directivas de planificación y organización, junto con la contratación de las personas idóneas para cada puesto, pueden no ser suficientes para la consecución de las metas empresariales. Las razones pueden encontrarse en una posible incompetencia del directivo o la falta de motivación de los trabajadores. Esta parte del manual se ocupa -en tres capítulos- (a) del análisis de los motivos impulsadores de la conducta del empleado y el ofrecimiento de la posibilidad de satisfacerlos en el trabajo; (b) del estudio de los estilos de dirección y el liderazgo y, finalmente (c) de la transmisión de la información en la cantidad y formas que imponga la estructura y recursos humanos de la organización.

Parte séptima: "Control". El control es la medición y corrección del desempeño a fin de asegurarse de que se cumple con los objetivos de la empresa y los planes diseñados para alcanzarlos. De hecho, la planificación y el control están estrechamente vinculadas, "son los gemelos idénticos de la administración" (Koontz y Weihrich, 1994), de aquí que hay autores que opinan que estas dos funciones no deben separarse. Dos capítulos analizan los elementos básicos del control, requisitos de un buen sistema así como los principales instrumentos del control de gestión. El último capítulo de este bloque realiza un sólido estudio de los sistemas de información para la administración.

Parte octava: "Temas especiales de Administración". Esta parte del manual recoge cuatro capítulos, que en opinión de los autores, son de difícil catalogación. Unos porque afectan a todos los aspectos de la gestión empresarial, otros porque integran cuestiones que reclaman un tratamiento diferenciado o bien porque no existen estudios suficientes que los relacionen mayoritariamente con alguna de las funciones directivas. En definitiva, este bloque 
pretende cerrar el análisis de la Administración con el trazado de temas que están suscitando el interés de los investigadores tales como la innovación, administración internacional... Por último, este bloque finaliza con dos capítulos dedicados a la administración en el futuro y otros temas de administración (creatividad, la negociación, análisis transaccional...) y un capítulo final que incluye dos casos generales al objeto de ofrecer una visión dinámica, compleja e interrelacionada de la realidad empresarial.

El manual teórico se acompaña de un "Libro de Actividades: casos, cuestiones y lecturas" complementario de la obra de Administración de empresas y que ha sido específicamente diseñado para utilizarse como apoyo docente. Su finalidad es intentar acercar al lector al desarrollo de capacidades de comprensión plena de los conceptos y de aplicación de los mismos a las decisiones reales. Este objetivo se logra mediante el empleo de tres recursos didácticos: casos, cuestiones de razonamiento y lecturas. Sesenta casos prácticos originales sobre organizaciones tan atractivas como Xerox, McDonald's, Benetton, Pepsico, Iberia, 3M, Chrysler, Coca-Cola, ITT, Microsoft...150 cuestiones de razonamiento (con la posibilidad de disponer del manual del profesor con amplias sugerencias de respuesta para la totalidad de cuestiones planteadas), 25 lecturas comentadas y 14 textos para el análisis hacen más sugerente la labor del docente en administración de empresas así como ofrece al lector interesantes conclusiones de las actuaciones empresariales. 